\title{
TRABALHO DOMÉSTICO É TRABALHO: discussões feministas no Cone Sul (1970-
}

1989)

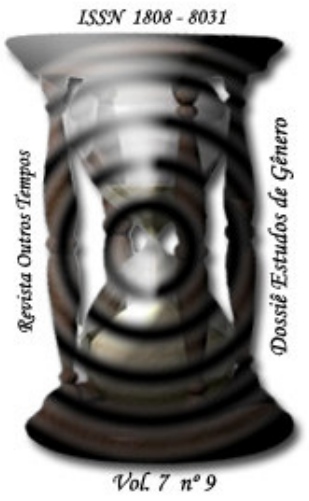

\author{
Soraia Carolina de Mello \\ Mestre em História Cultural ${ }^{1}$ pela Universidade Federal de Santa \\ Catarina \\ Soraiaa.melo@gmail.com
} pretende argumentar que trabalho doméstico também é trabalho, necessário e indispensável à vida humana. Para tal análise se utilizam periódicos produzidos por grupos feministas, além de bibliografia de referência sobre a questão, produção impressa a qual me fornece o recorte temporal do artigo.

Palavras-chave: Trabalho Doméstico; História do Feminismo; Cone Sul; Imprensa Feminista; Segunda Onda Feminista.

\begin{abstract}
The feminisms of what was called the Second-wave, more specifically the Southern Cone ones, are the object of my study. And it was through these feminisms that the issue of housework as a problem caught my attention. The relation between women and housework, even though affirmed by the feminisms and the gender studies as culturally built, has its main contribution in the naturalization of these functions. This article intends to deal with the discussion about these feminisms in search for the deconstruction of these naturalizations, in an attempt to argue that housework is also a kind of work, and it's necessary and indispensable to human life. Periodicals produced by feminist groups are used for such analysis, besides reference bibliography about the issue, wich gives me the clipping of time of the article.
\end{abstract}

Keywords: Housework; Feminism's History; Southern Cone; Feminist Press; Second-wave Feminism.

Artigo recebido em 31/3/2010 e aprovado em 31/5/2010.

${ }^{1}$ Este artigo é um recorte da discussão realizada na dissertação de mestrado intitulada "Feminismos de Segunda Onda no Cone Sul problematizando o trabalho doméstico (1970-1989)", defendida na Universidade Federal de Santa Catarina em 05 de março de 2010. A dissertação é dividida em duas partes, uma sobre o trabalho doméstico gratuito das donas de casa e outra sobre o emprego doméstico, trabalho realizado pelas empregadas domésticas. Por uma questão de delimitação, o presente artigo trata apenas do trabalho das donas de casa, sem ignorar nem a importância nem a desvalorização social que recai, historicamente, sobre o trabalho das empregadas domésticas, assim como sua relação com a saída das mulheres de classe média dos lares e também com a emergência dos movimentos feministas no Cone Sul. 
A discussão sobre o trabalho doméstico como um problema para as mulheres se faz presente na atualidade, e é uma das bandeiras de luta dos movimentos feministas que se mantém hasteada por cerca de quarenta anos, em maior ou menor intensidade. Observar de que forma, nos anos 1970-80, essa questão foi problematizada por mulheres organizadas com o intuito de reivindicar direitos específicos a elas, é também uma forma de tentar compreender em que momento histórico o trabalho doméstico se torna uma questão.

Os feminismos emergentes no Ocidente nas décadas de 1960-70 (os quais convencionou-se chamar de feminismos de Segunda Onda - a Primeira Onda do feminismo corresponderia às lutas sufragistas iniciadas no final do século XIX (PEDRO, 2006)) fazem parte de toda uma situação política e cultural, na qual as relações de poder são questionadas no âmbito público e privado. Velhos valores são desafiados por novos movimentos, e uma revolução voltada aos costumes e ao dia a dia toma forma (PINTO, 2003).

Com o surgimento de novas organizações de mulheres, e principalmente de novos feminismos $^{2}$ (não encontrei fontes que tragam movimentos de mulheres que não se digam feministas problematizando essa questão), o problema do trabalho doméstico como função "essencialmente" feminina é levantado. Essa preocupação pode ser observada nas discussões presentes em periódicos produzidos por diferentes grupos feministas do período. O jornal paulistano Nós Mulheres (1976-1978) é exemplar nesse sentido, principalmente em seus dois primeiros números. Referências a respeito também foram encontradas nos boletins feministas internacionais Isis e Mujer Ilet, no periódico argentino Persona, no boletim também argentino Brujas, no periódico paraguaio Enfoques de Mujer e no uruguaio Ser Mujer. Também consultei os jornais brasileiros Brasil Mulher e Mulherio. O Objetivo nesse artigo é, dialogando com bibliografia de referência (a qual, quando contemporânea às fontes, é tratada também como fonte), observar as formas pelas quais os

\footnotetext{
2 É importante ressaltar o cunho pejorativo que o feminismo carregava nesses anos. Diferenciam-se movimentos de mulheres e feministas pelo fato dos últimos terem suas reivindicações voltadas às questões específicas das mulheres. Grande parte dos movimentos de mulheres do período se declarava, inclusive, antifeminista, para se afastar das alcunhas de grupos de mulheres feias, mal-amadas e que odiavam homens. O jornal O Pasquim é uma boa fonte no que se refere aos estereótipos designados às feministas.
} 
feminismos de Segunda Onda no Cone Sul questionaram o fato do trabalho doméstico não ser considerado trabalho.

\section{Por que o trabalho doméstico não é considerado trabalho?}

As donas de casa estão manifestando, em cartas ou em debates, palestras nos quais temos participado, uma grande angústia relativa à vida em caso de viuvez ou separação. Essa angústia é totalmente compreensível. A única trabalhadora que não tem a menor garantia quanto ao seu futuro é a dona de casa. Embora exerça funções as mais complexas e tenha sob sua responsabilidade tarefas consideradas de suma importância para o sistema, a dona de casa tem sido a mais relegada, a mais desprezada, a mais discriminada. É a única que não recebe salário, não tem férias, não tem $13^{\circ}$ salário, fundo de garantia ou descanso semanal etc., etc. (CARDOSO, 1982, p. 60)

A dona-de-casa (sic) maneja objetos cujo valor de uso transforma, depositando neles seu trabalho e aumentando seu valor. Seu trabalho de transformação material de bens é tão necessário que uma greve geral das donas-de-casa produziria um desabamento imediato de toda a economia. É um trabalho coletivamente necessário e não faz sentido catalogá-lo como produtivo ou improdutivo, sobretudo quando na linguagem comum se tende a equiparar o produtivo com o necessário ou com o útil. Não existe nenhum trabalho tão necessário em nossa economia como o das donas-de-casa e nas condições atuais, a divisão das tarefas que elas fazem, entre os trabalhadores da economia exterior, requereria uma massa de trabalhadores três vezes maior do que o número atual de trabalhadoras nas economias domésticas. (Grifos da autora) (DURAN, 1983, p. 20-21)

Estudos e pesquisas realizados nos últimos anos no Brasil têm revelado que a mulher continua em grande medida a ser a trabalhadora mais marginalizada e mais mal remunerada, aquela que sofre toda sorte de discriminação no mercado de trabalho e que continua a não poder contar com o auxílio de equipamentos coletivos, de instituições sociais, sem que exista uma valorização social de sua contribuição para a produção doméstica e a reprodução da força de trabalho. Coube principalmente ao movimento feminista - o grande impulsionador de tais estudos e pesquisas - chamar a atenção para a significação econômica e política do trabalho doméstico para a sociedade e destacar a importância do papel desempenhado pela dona-de-casa. (sic) (TABAK, 1983, p. 67-68)

Essas citações nos apresentam alguns dos exemplos, dentre tantos que as fontes consultadas oferecem, de discussões feministas a respeito da desvalorização e invisibilização do trabalho doméstico. Se os feminismos de Segunda Onda se caracterizaram por problematizar a divisão sexual do trabalho, dentro e fora dos lares, como uma questão fundamental da opressão feminina, e por destacar a necessidade de valorização social do trabalho doméstico gratuito desempenhado pelas mulheres, eles não o 
fizeram de forma unívoca. Na busca por reconhecimento social das tarefas das donas de casa como trabalho, alguns caminhos, às vezes dissonantes, foram tomados, tanto tentando explicar como surge essa divisão e desvalorização de tarefas, quanto no apontamento de possíveis soluções para o problema. $\mathrm{Na}$ imagem 1, abaixo, retirada do décimo número do Mulherio, de 1982, podemos ver uma charge que explicita a quantidade de trabalho desempenhado por uma dona de casa, ao mesmo tempo em que problematiza sua invisibilidade.

Também no boletim Nosotras de mulheres latino americanas em Paris, em seu número 25-26, de 1976, encontramos a questão. Neste, são divulgados temas denunciados no Tribunal Internacional dos Crimes Cometidos contra as Mulheres, que ocorreu em Bruxelas, de 04 a 08 de março de 1976. Entre as denúncias, vale destacar, há o item "discriminação no trabalho e não reconhecimento do trabalho doméstico."3

Uma das questões apresentadas a respeito da desvalorização e não reconhecimento do trabalho doméstico está ligada ao fato desse trabalho não se encaixar nos conceitos de trabalho regularmente utilizados. Cristina Bruschini, em pesquisa divulgada no Mulherio número 21, "Desvendando uma trama invisível", afirma que

A realização desta pesquisa me permitiu ter um quadro amplo sobre o trabalho da mulher e chegar a algumas conclusões importantes. A primeira é relativa ao próprio conceito de trabalho, que precisa ser redefinido para que nele caibam trabalho doméstico, trabalho a domicílio e tudo aquilo que as pessoas fazem e contribui para a produção social. Não falo só de mulheres, mas também de velhos, jovens e até crianças. A pesquisa sobre mulher nos permite olhar para as estatísticas sabendo que elas revelam apenas um pedaço daquilo que as pessoas fazem. ${ }^{4}$

\footnotetext{
${ }^{3}$ Nosotras. Paris, $\mathrm{n}^{\circ}$ 25-26, 1976. P. 24.

${ }^{4}$ Mulherio. São Paulo, Ano 5, no 21, abril/maio/junho de 1985. P. 20.
} 


\section{Imagem 1}

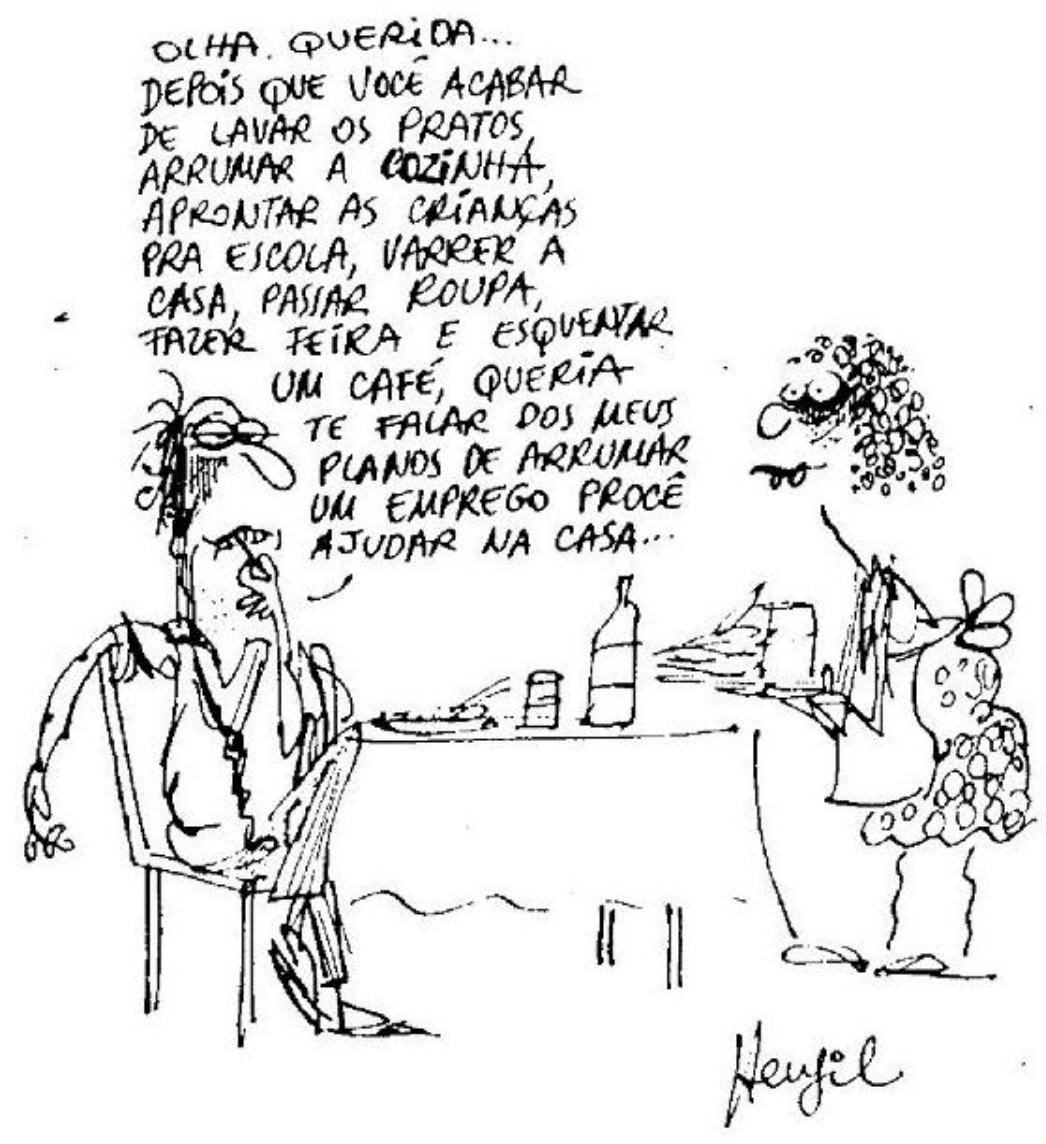

É algo no sentido do que Cristina Carrasco afirma em nossos dias, que “(...) não se aceita que, além do trabalho de mercado, possam existir outros trabalhos com igual ou maior valorização social" (CARRASCO, 2008, p. 99). Inclusive, segundo bibliografia consultada, essas questões continuam muito presentes. Avanços, por vezes tímidos, na divisão mais igualitária das tarefas nos lares entre os casais, podem ser percebidos, mas a desvalorização fundamental do trabalho doméstico e sua associação, ainda que simbólica, com as mulheres, perdura.

A produção de bens e serviços que tem lugar na esfera familiar, ou que se encaminha por meio do trabalho não remunerado, não tem visibilidade pública

\footnotetext{
${ }^{5}$ Mulherio. São Paulo, Ano 2, $\mathrm{n}^{\circ}$ 10, novembro/dezembro de 1982. P. 07. "Olha, querida... Depois que você acabar de lavar os pratos, arrumar a cozinha, aprontar as crianças pra escola, varrer a casa, passar roupa, fazer feira e esquentar um café, queria te falar dos meus planos de arrumar um emprego procê ajudar na casa...”
} 
nem ao menos nos registros trabalhistas, razão pela qual tendeu a ser considerada como não-trabalho, segundo a clássica associação entre trabalho e emprego remunerado. Do mesmo modo, a divisão do trabalho por sexo, consolidada desde a industrialização, associa (mais no imaginário coletivo do que na realidade) a atividade masculina com a produção mercantil e a feminina com a atividade familiar doméstica. (...) Essa rígida distribuição de tarefas levou à ocultação da contribuição de uma parte significativa do trabalho realizado pelas mulheres para o bem-estar familiar e social. (ARRIAGADA, 2007, p. 243)

Cristina Torres comenta em 1988 que, ao se analisar o trabalho doméstico, a questão não é se ele é trabalho no sentido de "atividade do homem sobre a natureza para satisfazer suas necessidades", porque nessa definição ele se enquadra muito bem. O problema seria aquilo que o trabalho doméstico não é: ele não tem ciclos de acumulação, não estabelece relações salariadas e seus produtos não têm preço no mercado (TORRES, 1988, p. 03). A partir disso a autora apresenta dois problemas centrais na desvalorização e invisibilidade do trabalho doméstico: a dificuldade para medição desse trabalho em termos estatísticos, e a subestimação de índole cultural que recai sobre o trabalho doméstico.

Considerando a invisibilidade do trabalho doméstico como construída, os feminismos de Segunda Onda colocam em primeiro plano a visibilidade, para então questionar por que essa é uma ocupação quase que exclusivamente feminina. Mas o que, além dos censos, contribuiria para tal invisibilidade? Em Persona podemos encontrar uma resposta

(...) Vivemos em uma sociedade regida pela produção de mercadorias, que são fabricadas com o fim de serem vendidas e compradas. Isso produz dinheiro, que é o capital, indispensável para poder fabricar, vender e comprar. "O capitalismo é a primeira sociedade da história humana em que a maior parte da produção é produção de mercadorias". As mulheres em suas casas realizam uma quantidade de coisas que não se vendem e que não se compram, mas que estão destinadas a serem consumidas pela família, portanto esse trabalho não produz dinheiro, é uma produção sem valor. É uma flagrante contradição e um problema crucial que isso ocorra um uma sociedade cujo valor dominante é o dinheiro. $(\ldots)^{6}$

E o artigo segue falando dos censos, e de como as mulheres são consideradas inativas ou improdutivas por não participarem diretamente do ingresso de renda na família. Ou seja, como colocado recentemente por Irma Arriagada, “A falta de valoração monetária

\footnotetext{
${ }^{6}$ Trecho do artigo "La Profesión: Ama de Casa", do primeiro número do Persona. Minha tradução.
} 
do trabalho doméstico não remunerado impede de avaliar a real contribuição econômica das mulheres (...)." (ARRIAGADA, 2007, p. 244)

Isso nos traz uma discussão que está presente nas fontes observadas, que é a do trabalho doméstico como trabalho produtor ou apenas reprodutor da força de trabalho. O Brujas, em artigo intitulado "El feminismo como ideologia y como practica politica", de 1984, afirma

(...) A respeito do trabalho doméstico, existem numerosos estudos feministas, que - com algumas divergências teóricas acerca do caráter desta produção concordam em afirmar que se trata de um trabalho produtivo realizado gratuitamente pelas mulheres no seio da família e cujo caráter de trabalho se faz "oculto" por uma visão naturalista que o considera uma tarefa "natural" das mulheres.-

Economistas do Terceiro Mundo e feministas descobriram que a acumulação capitalista resultante da mais-valia (aquela extraída exclusivamente do trabalho mercantil) se alimenta também na acumulação permanente de base, ou seja, aquela baseada na exploração do trabalho doméstico não mercantil realizado pelas mulheres no lar, trabalho que permite a produção e reprodução da força de trabalho do marido e filhos a menor custo.-

Por fim, todos esses estudos colocam em evidência que a produção doméstica é uma categoria econômica e não uma fatalidade biológica. (.... ${ }^{7}$

Uma carta enviada ao Nós Mulheres e publicada em seu primeiro número, em

1976, também nos traz essa questão

Ao meu ver, o grande, o básico problema feminino, é a desvalorização do trabalho doméstico - causada pelo advento do mercantilismo, e a valorização social com base na remuneração financeira do trabalho. É a economia do mercado e a sua mentalidade corruptora que provocaram a degradação do papel doméstico, socialmente tão importante como o da produção de alimentos.

Ninguém vai me convencer que lixar as unhas de um executivo numa barbearia seja mais importante que mudar as fraldas de um filho em casa. Nem que seja mais útil, ou mais necessário. O trabalho, porém, não vale por seu produto, e sim por seu preço. Essa é a primeira distorção mercantilista, totalmente absorvida e levada a seus últimos extremos pelo capitalismo. $(. .)^{8}$

Mirta Henault afirma, em nossa década, que "Nem a economia clássica, nem o marxismo científico estimaram como produtivo o trabalho da mulher em casa" (HENAUT, 2001, p. 52). Para Fatiha Hakiki-Talahite, em trabalho publicado no final dos anos 1980, a

\footnotetext{
${ }^{7}$ Brujas. Buenos Aires, Ano 2, no 6, 1984. P. 10-11. Minha tradução, os grifos não.

${ }^{8}$ Trecho da carta de Tânia Jamardo Faillacce, de Porto Alegre - RS, extraída do Jornal Nós Mulheres. São Paulo, $\mathrm{n}^{\circ}$ 1, junho de 1976. P. 18.
} 
questão era outra. Refletindo sobre o que chama de "processo de trabalho doméstico" (conceito que não envolveria apenas o trabalho em si, mas suas imbricações sociais, culturais e históricas) e as tentativas de valorá-lo economicamente, a autora argumenta

\footnotetext{
É importante precisar que, mesmo como teoria da medida do valor, a Economia Política não pode integrar o trabalho doméstico, pelo fato que ela supõe a troca mercantil. Igualmente, as tentativas de construir uma teoria do trabalho doméstico fundada no reconhecimento dos produtos deste último como valor situam-se, à primeira vista, de maneira instável em relação ao campo no qual elas pretendem se inscrever, qualquer que seja, aliás, a definição de valor que adotem (...). (Grifos da autora) (HAKIKI-TALAHITE, 1986, p. 97)
}

Quer dizer, dentro da teoria econômica e do conceito de valor desta, o trabalho doméstico feminino não teria espaço. Ele não poderia ser considerado produtivo porque a noção de trabalho produtivo da economia não se aplica a ele. Entretanto, a economista Maria Angeles Duran critica o pressuposto de que o trabalho doméstico, por ser improdutivo, não teria valor (DURAN, 1983, p. 12). A autora, ao afirmar que trabalho doméstico é trabalho, busca afirmar que negar o caráter de trabalho do trabalho doméstico seria apresentá-lo como natural. Quer dizer, parece que deixa de ser trabalho porque é realizado na família, mas isso seria mais uma característica especial e, esse trabalho, de tão comum e numeroso, deveria ser considerado a regra, não a exceção. A diferença central em comparação com os demais trabalhos seria o fato de eles serem relativamente livres, intercambiáveis e contratados (DURAN, 1983, p. 17-18). Conforme a própria autora, em 1983

(...) por ser um trabalho de manutenção que se destrói quando se produz, mal permite visualizar sua acumulação e, como tal, perceber sua contribuição para a criação de riqueza e, menos ainda, ser trocado pelo resultado de outros trabalhos em outras unidades econômicas. Não é possível a troca, a objetivação por dinheiro, e nem sequer a permuta. (DURAN, 1983, p. 25).

A partir disso, Cristina Carrasco argumenta recentemente que "Explicitar, nos esquemas econômicos, o trabalho familiar doméstico como trabalho necessário é uma questão de justiça, mas também de sensatez e rigor, caso se pretenda analisar e interpretar a realidade." (CARRASCO, 2008, p. 96) O fato do conceito econômico de valor, nas sociedades estudadas, ser interpretado também como valor social, leva as feministas, a 
partir dos anos 1960 e 1970, a questionar as bases da economia clássica nas quais se alicerçam o conceito.

(...) a própria definição das fronteiras da economia (neoclássica e outras) - que considera apenas a economia de mercado - é estreita e excludente e não permite a análise do trabalho não remunerado, atividade básica para a sustentabilidade da vida humana e para a reprodução da força de trabalho de mercado. (...) A cegueira analítica decorrente desse enfoque não deixa que os homo economicus sejam vistos como seres completamente dependentes das mulheres em tudo o que se refere às atividades de cuidados, sem as quais eles nem sequer existiriam. (CARRASCO, 2008, p. 92)

Essa observação de Cristina Carrasco é recente, mas dialoga diretamente com Maria Angeles Duran, que 25 anos antes escreve que "Muitos homens passam a vida inteira sem perceber que a base econômica de sua família seja mais sua esposa do que eles mesmos." (DURAN, 1983, p. 15) Esse tipo de constatação pode nos levar a pensar que o debate, de alguma forma, se estagnou nesses últimos anos, ou talvez seja um debate que não se difundiu o suficiente para se desenvolver por outros caminhos. Ou, simplesmente, pode ser uma questão que se mantém viva por não ter encontrado resoluções concretas, até porque as transformações nunca são lineares e homogêneas, e o que pode ser considerado novo e tradicional convive e interage o tempo inteiro na história. De qualquer forma, são questões colocadas pela Segunda Onda Feminista que permanecem na pauta de reivindicações dos feminismos na atualidade.

Um dos pontos elencados nesse debate é o que defende que o trabalho doméstico é desvalorizado porque é observado através de uma perspectiva masculina. Em Mirta Henault, em 2001, encontramos uma crítica no que se refere às análises a respeito da desvalorização do trabalho doméstico. A autora sustenta que os problemas referentes à individualidade das mulheres estão ligados ao olhar masculino, androcêntrico, que se dá sobre suas atividades.

O trabalho doméstico é, sem dúvida, o trabalho "natural" da mulher. Repetitivo, monótono, sem fim. Não criativo, segundo o conceito de criatividade dos homens. Não produtivo, de acordo com a relação patriarcal de produçãodinheiro. O trabalho, enorme trabalho de cuidar da espécie apenas merece uma menção de "boa dona de casa". Não é rentável nem produz dividendos. (Minha tradução) (HENAUT, 2001, p. 24) 
Fatiha Hakiki-Talahite, ao criticar a exclusão do trabalho doméstico nas teorias econômicas, comenta que essa exclusão realizada pelos economistas clássicos nos séculos XVII e XVIII até pode ser justificada, mas que atualmente (na época de sua publicação, meados dos anos 1980) seria difícil negar a existência do trabalho doméstico como "fenômeno amplo e sistemático, que merece ser inscrito estruturalmente no estudo da economia contemporânea" (HAKIKI-TALAHITE, 1986, p. 98). Entretanto, relata como essa exclusão continua presente na

(...) categoria de indivíduo, de homo-economicus, que sob a aparência de um ser genérico, possui, em realidade, todas as características - masculinas - de um bom pai de família. (...) Nesse universo, a mulher não existe enquanto indivíduo; a sociedade é considerada como uma coleção de indivíduos-homens que têm necessidades, recursos, um lugar na divisão do trabalho, uma renda e ... uma família, isto é, obviamente, mulher e filhos...” (Destaques da autora) (HAKIKITALAHITE, 1986, p. 98)

Quer dizer, a autora critica também a questão do masculino como universal, que promove a exclusão das mulheres na medida em que elas nunca poderão se enquadrar na norma. Nesse caso, a norma, o padrão de normalidade, do que seria saudável e positivo, é ditado pelas teorias econômicas, e é masculino.

Outra das discussões que giram em torno da análise econômica do trabalho doméstico é a respeito do barateamento dos salários que esse trabalho gratuito das mulheres proporcionaria. Quer dizer, se as mulheres não desempenhassem esses serviços em casa, as famílias seriam obrigadas a pagar por eles, o que exigiria maiores salários. Jesus Albarracín explica bem essa relação em nossos dias, onde coloca que, apesar de não ser regulado pela lei do valor, o trabalho doméstico não independe dessa lei, e também se encontra intimamente relacionado com a mais-valia (ALBARRACÍN, 1999, p. 43-61).

Ou seja, se o trabalho doméstico não fosse feito gratuitamente, os/as trabalhadores/as precisariam de um salário maior para sua subsistência, para poder pagar por esse tipo de serviço. O autor ainda coloca que, com a incorporação de mulheres no trabalho assalariado, mantendo as responsabilidades do trabalho doméstico, ao capitalista surge a oportunidade de reduzir os salários, uma vez que o salário masculino não precisa mais sustentar a casa toda, pois tem o da mulher para "ajudar". Assim, o autor relaciona trabalho doméstico, trabalho assalariado e mais-valia, e admite que o trabalho doméstico, 
apesar de estar fora dos circuitos de mercado, é de grande serventia para o funcionamento deles.

Vale ressaltar certa ambigüidade que parece estar presente no discurso de Jesus Albarracín. Ao mesmo tempo em que este admite a "serventia" do trabalho doméstico, parece culpar a entrada das mulheres no mercado de trabalho pela baixa de salários e, ainda, não considerar a função reprodutora da força de trabalho que as atividades domésticas representam. Entretanto, Jesus Albarracín traz uma questão que foi importante ponto de discussão nos feminismos de Segunda Onda, e que abriu brecha para outras discussões nesse sentido. Cristina Torres por exemplo, sobre a questão do barateamento de salários, admitiu que o trabalho das mulheres fora de casa poderia baratear alguns salários, como por exemplo do operariado, no que se refere à concorrência ou disponibilidade para emprego de meia jornada. Entretanto, simultaneamente, essa saída das mulheres de casa poderia aumentar o preço de prestações de serviço necessárias devido a sua ausência, e que se valorizam conforme aumenta a demanda (TORRES, 1988, p. 04). Quer dizer, ao mesmo tempo em que barateava alguns salários, encarecia outros.

Outro ponto subjacente a esse debate é o das mulheres como exército de reserva de mão-de-obra para o capitalismo. O tópico Um bom disfarce do desemprego, do artigo "Dona de casa: qual o reino desta rainha?"," publicado no segundo número do Nós Mulheres, em 1976, levanta, ainda que implicitamente, o papel de reserva de mão-de-obra que as donas de casa representam. Heleieth Saffioti, em Emprego Doméstico e Capitalismo, de 1978, observa a maneira como o modo de produção capitalista coexiste com formas não capitalistas de trabalho (como seria o caso do trabalho doméstico não remunerado).

Assim, em momentos de expansão do capitalismo, a força de trabalho se deslocaria para suas atividades, retornando às atividades não capitalistas em um momento de retração do mesmo. A produção capitalista não teria interesse em eliminar essas formas não capitalistas de trabalho, uma vez que esse excedente de mão-de-obra representaria um exército de reserva. A existência desse exército seria imprescindível para que a exploração capitalista do trabalho conseguisse manter sua lógica funcionando, e aí se encontraria outra

\footnotetext{
${ }^{9}$ Nós Mulheres. São Paulo, no 2, setembro/outubro de 1976. P. 08-09.
} 
razão para que não se tivesse interesse em eliminar o trabalho gratuito desempenhado pelas mulheres dentro da lógica capitalista (SAFFIOTI, 1978, p. 183-197).

Sobre essa questão, um depoimento reproduzido pelo Nós Mulheres, no artigo supracitado, se faz pertinente: a entrevistada gostaria de ter trabalhado quando teve oportunidade, mas precisou ficar cuidando das filhas. Agora elas cresceram, ela ainda gostaria de ir trabalhar, mas então percebeu que é de fato uma desempregada. Faz parte do exército de reserva. Porém, vale atentar para o fato de que Heleieth Saffioti faz sua análise não considerando o papel reprodutor de mão-de-obra capitalista do trabalho doméstico, como o fazem trabalhos anteriormente aqui citados. Caso ela o fizesse, a divisão entre formas de trabalho capitalistas e não-capitalistas não poderia ser sugerida com tanta segurança, uma vez que a atenção estaria voltada para a relação entre essas formas de trabalho, e não para a separação entre elas.

Fatiha Hakiki-Talahite entende o processo de trabalho doméstico como separado e oposto ao processo de trabalho do capital, ao mesmo tempo em que é unido a ele, pois são dois momentos de um único e mesmo movimento e um não poderia existir sem o outro. Quer dizer, não se poderia imaginar nem uma sociedade capitalista total, sem o trabalho doméstico gratuito, nem que o processo de trabalho doméstico fosse inteiramente subordinado às necessidades do capital (HAKIKI-TALAHITE, 1986, p. 109). Já Cristina Torres, em escrito quase contemporâneo ao de Fatiha Hakiki-Talahite, apresentando um debate teórico a respeito do trabalho doméstico que buscava encaixá-lo na idéia de um modo de produção peculiar ou então de uma atividade subordinada ao capitalismo, buscou observar esse trabalho como um conjunto de relações articuladas com o modo de produção capitalista, quer dizer, como um trabalho paralelo porém subsidiário do capitalismo (TORRES, 1988, p. 04). A autora também comenta rapidamente a questão da mão-de-obra de reserva, constatando que era comum as mulheres uruguaias deixarem seus trabalhos fora de casa quando se tornavam mães, retornando, quando possível, apenas após as crianças já estarem maiores (TORRES, 1988, p. 22).

No editorial do Isis número 11-12, de 1982, afirma-se sobre a questão que "Esta ideologia ou cultura de opressão da mulher proporcionou socialmente uma força de trabalho barata, paciente e facilmente manejável, que pode ser desprezada ou utilizada 
segundo os vaivens da economia e das ânsias de lucro dos empresários." ${ }^{10}$ Já no boletim Nosotras de mulheres latino americanas em Paris, em seu sétimo número de 1974, há uma matéria que se refere ao Brasil, intitulada "As verdadeiras razões do incentivo à mão de obra feminina no Brasil" "1, que critica o incentivo do trabalho de mercado das mulheres encabeçado pelo governo. No artigo, primeiramente se apontam como slogans ideológicos, ou falsas razões para esse incentivo, a emancipação da mulher através da independência econômica e a realização individual. Então são listados interesses das empresas privadas e do governo, com o intuito de denunciar as péssimas condições de emprego oferecidas às mulheres.

É necessário aos Estados e às emprêsas privadas:

1) que a mulher seja mantida na condição permanente de dona-de-casa para realizar sua dupla função social:

A) como reprodutora da mão-de-obra (na qual reside a fôrça econômica do país) e;

B) como fôrça produtora gratuita da infra-estrutura familiar (manutenção física, psíquica e moral, além de ideológica) do marido e dos filhos - na qual repousa a certeza da continuidade do Sistema.

2) Mantêr uma mão-de-obra de reserva a qual se possa recorrer de imediato nas crises, compensando assim um desequilíbrio momentâneo;

3) que a mulher preencha os emprêgos de infra-estrutura, desprezados ou pouco aceitos pelos homens. (...) (sic)

Na década de 1970, a questão da subordinação das mulheres de forma mais geral começa a ser discutida de um ponto de vista econômico, onde a teoria marxista se sobressai, principalmente apoiada pela presença de feministas socialistas. Margareth Benston foi apontada como pioneira em observar a opressão das mulheres como uma opressão econômica (BENSTON, 1969, p. 87). Com o trabalho doméstico em discussão, não é de se estranhar o surgimento de tal posição, considerando o momento, no qual teorias marxistas tomam força juntamente com as soluções economicistas.

Dentre os nomes que surgem discutindo o trabalho doméstico sob um viés econômico, ganha destaque Cristine Dupont, que considera as mulheres a classe oprimida de um sistema que não o capitalista, mas o familiar ${ }^{12}$, ou patriarcal (DUPONT, 1978, p. 88-

\footnotetext{
${ }^{10}$ Editorial. ISIS - Boletin Internacional. Itália/Suíça, no 11-12, outubro/dezembro de 1982. P. 04. Minha tradução.

${ }^{11}$ Nosotras. Paris, Ano 1, $\mathrm{n}^{\mathrm{o}}$ 7, 1974. Pg 11.

${ }^{12}$ Referência que defende posição semelhante pode ser encontrada na página 28 do $5^{\circ}$ número do Persona, no artigo intitulado "Las mujeres - una casta", o qual afirma: "Se é certo que a relação com a produção é o que
} 
89). E essa opressão é agravada pelo fato de que as mulheres não mudam de emprego, nem recebem por seu trabalho. Assim, a exploração da força de trabalho gratuita feminina se dá dentro do casamento, e essa opressão comum a todas as mulheres faz com que elas pertençam a uma classe diferente da dos seus maridos. Também ganha destaque Mariarosa Dalla Costa, explicitando que além de produzir valores de uso (como coloca Cristine Dupont), o trabalho doméstico também é uma função essencial na produção da mais-valia (teoria utilizada por Jesus Albarracín). Suas teorias serviram de apoio para as primeiras campanhas pelos salários para donas de casa ${ }^{13}$, considerando que estas produzem uma "mercadoria" para o capital, que seria seu marido e seus filhos, ou seja, a força de trabalho (COSTA, 1975, p. 90). Essas teorias foram contestadas por diferentes análises econômicas e, em especial a questão sobre o trabalho doméstico ser produtivo, improdutivo, ou reprodutivo, se mantém em discussão e até hoje não chegou a um consenso total, apesar da idéia de trabalho doméstico como trabalho de reprodução ser a mais corrente (HENAUT, 2001, p. 46).

E é com base nessa noção, do trabalho doméstico como atividade de reprodução social, que se indica mais um âmbito no qual se construiu a desigualdade entre homens e mulheres: a subordinação social, cultural e histórica da reprodução à produção. Refletindo a esse respeito em nossa década, Mirta Henault busca uma inversão desses valores de desigualdade.

\footnotetext{
Considerar a reprodução da força de trabalho, o papel do trabalhador no processo produtivo e as mulheres como exército industrial de reserva, levaram à conclusão de conceder à reprodução humana a mesma importância conceitual que à organização da produção assalariada (contribuição do feminismo nessa reconceituação). (...) Também poderíamos dizer que os trabalhos para o mercado são subsidiários em relação aos trabalhos de reprodução e com mais razão dependentes destes últimos. (Minha tradução) (HENAUT, 2001, p. 46)
}

Danièle Combes e Monique Haicault comentam, em meados dos anos 1980, a contradição no fato da reprodução estar subordinada à produção, e não o contrário. Esse

determina a posição social dos indivíduos, não haverá nenhuma dificuldade em aceitar que "mulher" indique uma situação social precisa, na qual cada mulher compartilha a mesma relação fundamental de produção, ou seja, o trabalho doméstico."

${ }^{13}$ Nós Mulheres. São Paulo, no 2, setembro/outubro de 1976. P. 15. 
seria um fato anterior ao capitalismo que se apoiaria em outra subordinação, a das mulheres aos homens, sobre a qual repousaria a divisão sexual do trabalho.

(...) enquanto o bom senso ou a utopia recomendaria que a primeira fosse submetida à segunda como o meio ao fim, e que os seres humanos produzissem bens para subsistir e se perpetuar, que organizassem essa produção em função da reprodução, é o inverso que se produz historicamente e são as modalidades da produção que determinaram e determinam ainda as modalidades da reprodução. $\mathrm{O}$ surgimento e o desenvolvimento de um modo de produção que transforma o próprio ser humano numa mercadoria apenas confirmam (e simbolizam) a subordinação da reprodução à produção, fato anterior ao capitalismo e capaz de sobreviver a ele. (COMBES; HAICAULT, 1986, p. 25)

As autoras ainda se preocupam em apontar que a divisão sexual do trabalho não é total, não é encontrada de forma "pura" nas sociedades, mas existe e é marcada. Da mesma forma, reforçam a idéia de que o trabalho doméstico não existe em função do capitalismo, que não é uma necessidade deste nem está presente apenas nele, citando que a subordinação da reprodução à produção e todos os fatores imbricados nesta estão presentes em formações sociais e modos de produção muito variados. Essa insistência é justificada como contraponto às análises correntes na época, que consideravam "o capitalismo como fundamento único da realidade social atual e, particularmente, como origem do trabalho doméstico e da organização da reprodução, entendida como uma necessidade específica e, além do mais, tardia do modo de produção capitalista” (KERGOAT, 1986, p. 83).

Entretanto, alegam que isso não quer dizer que o advento do capitalismo não venha a transformar a produção e a reprodução. "E a história do capitalismo será igualmente, e desde o início, a história de uma nova organização da reprodução." (COMBES; HAICAULT, 1986, p. 27) Nesse sentido, apontam que é a partir do advento do capitalismo que a reprodução passa a ser uma questão estatal ${ }^{14}$, uma vez que há a preocupação pública com a geração e manutenção da força de trabalho. Mas vale colocar aqui, de forma mais clara, o posicionamento teórico das autoras - Danièle Combes e Monique Haicault - nesse campo.

Ao mesmo tempo em que admitem a relação da produção com a reprodução, defendendo inclusive uma análise conjunta dessas esferas a partir das relações entre as

14 Também em Fatiha Hakiki-Talahite encontramos a noção de que a família moderna, tal como a conhecemos, é uma criação recente, normalizada pelo Estado (ou pelos estados). HAKIKI-TALAHITE, F. Por uma problemática... Op. Cit., 1986. P. 95. 
classes e das relações entre os sexos, elas criticam veemente e repetidamente uma espécie de reducionismo, calcado na tradição marxista, o qual analisaria a família apenas como local de consumo e de reprodução da força de trabalho, ou seja, como um simples instrumento a servir o modo de produção capitalista. Quer dizer, ainda que sua teoria esteja também calcada na teoria marxista, há uma crítica interna presente, preocupada com as relações sociais ${ }^{15}$, buscando assim entender a família como esfera e como força em jogo na luta de classes e dos sexos.

Podemos encontrar essas preocupações também em Fatiha Hakiki-Talahite. Ela comenta como muitos autores tentaram elaborar uma "economia da família", buscando acabar com esse reducionismo da família como unidade de consumo apenas, e como a partir desses estudos, as fronteiras entre trabalho/lazer, produção/consumo, atividade/inatividade, etc. se deslocam (HAKIKI-TALAHITE, 1986, p. 98-99). Ela critica as correntes que interpretam o trabalho doméstico como produtivo por produzir força de trabalho. Acredita que essas correntes tendem a simplificar um processo complexo, ao considerar a força de trabalho um produto igual a qualquer outra mercadoria no mercado, e propõe se pensar em termos não de produtos apenas, mas do trabalho doméstico através da linguagem, da cultura, do imaginário, do corpo e da sexualidade das mulheres, entre outros fatores (HAKIKI-TALAHITE, 1986, p. 111). Entretanto, a autora não está, também ela, negando totalmente teorias e conceitos marxistas. Ela utiliza a noção de "expropriação das mulheres" para explicar o processo de exclusão que estas sofrem a partir do assalariamento, quando seu trabalho é totalmente separado do trabalho produtivo (HAKIKI-TALAHITE, 1986, p. 110- 111).

Danielle Chabaud e Dominique Fougeyrollas-Schwebel, dialogando com as autoras supracitradas, não negam a família como espaço de reprodução da força de trabalho, mas buscam nuançar a questão a partir do espaço social de onde se parte para observá-la

Para o modo de produção capitalista, trata-se de assegurar a reprodução das forças de trabalho sobre as quais ele repousa. Para os trabalhadores, a família pode ser vivida como um lugar de autonomia preservado da vida de trabalho, um

\footnotetext{
15 A idéia de relações sociais discutida em todo o livro de onde o texto citado foi retirado, implica contradição, antagonismo, luta, recusa... Talvez uma solução teórica para escapar de reducionismos propostos por um marxismo mais "duro", para não dizer ortodoxo, já que não considero o termo apropriado. "Em resumo, o que é importante na noção de relação social - definida pelo antagonismo entre grupos sociais - é a dinâmica que ela reintroduz (...)". KERGOAT, D. Em defesa de... Op. Cit., 1986. P. 82.
} 
lugar de resistência contra a exploração do trabalho industrial. (CHABAUD; FOUGEYROLLAS-SCHWEBEL, 1986, p. 113-114)

Diferente da noção de "expropriação das mulheres" de Fatiha Hakiki-Talahite, Cristina Torres quase no mesmo período fala da apropriação do trabalho da dona de casa, constatando que este não se daria por um empresário concreto, uma vez que essa trabalhadora não tem um patrão, mas ocorreria através do sistema em seu conjunto, uma vez que o trabalho da mulher em casa excederia as necessidades da sua própria reprodução, convertendo-se em trabalho subsidiário não pago pelo capital, transferido ao capital através dos filhos que constituem a força de trabalho (TORRES, 1988, p. 02). A autora também lembra que a carga de trabalho das donas de casa pode variar segundo a extensão da família, mas também por questões de classe. Por exemplo, ela observou como os custos altos das prestações de serviço e os baixos salários oferecidos no mercado tenderiam a manter as mulheres de baixa renda, principalmente as que são mães, em casa, uma vez que a elas não compensaria sair para trabalhar, situação diferente da encarada por mulheres das camadas médias e altas (TORRES, 1988, p. 12).

Nesse sentido, podemos observar como as discussões dos feminismos estudados estão dialogando constantemente com discussões marxistas, e como as questões das mulheres estão, nessas publicações, imbricadas com as questões de classe. Danièle Kergoat comenta, em 1986, a necessidade de não hierarquizar as relações sociais, ao considerar as relações entre classes mais importantes que as entre os sexos, ou vice-versa. Ela parte da idéia de que não há um front principal, ou inimigo principal (KERGOAT, 1986, p. 83). É provável que essa questão apresentada por Danièle Kergoat não seja apenas um problema teórico, mas uma proposição de diálogo, de caminho comum, entre movimentos de esquerda e feministas. Também podemos reconhecer uma crítica colocada pela autora, quando usa o termo "inimigo principal”, a grupos e teóricas feministas que, em crítica ao marxismo e à idéia de que o capitalismo seria o inimigo principal, colocam o patriarcado ${ }^{16}$ como tal.

\footnotetext{
${ }^{16}$ A idéia de uma ordem ou sistema patriarcal, que legitimaria e manteria a opressão das mulheres, foi muito corrente nos feminismos de Segunda Onda. Apesar de no Brasil esse conceito ter perdido força, ele ainda é encontrado e, em outros países da América Latina parece ser mais corrente. Exemplos em HENAUT, M. De la rueca... Op. Cit., 2001; e em BEDREGAL, Ximena. Con mi feminismo mirando al Sur. Disponível em http://www.creatividadfeminista.org. Acesso em 15/03/2007.
} 
Danièle Kergoat, assim, propõe uma análise conjunta, mas observa como na prática seria difícil conciliar as questões de classes e de sexos, e como as dicotomias se reproduziam também nas pesquisas. Então, busca como solução para se analisar as questões das relações entre os sexos (as quais hoje provavelmente chamaríamos de gênero, incluindo na discussão a questão relacional imbricada no conceito), a retomada teórica, com adaptações e reelaborações, dos conceitos marxistas, por entender que são “(...) conceitos que foram forjados para explicar a luta de dominados contra dominadores (...)" (KERGOAT, 1986, p. 93). Por essa ou por outras razões, ao menos nas publicações aqui observadas, podemos encontrar elaborações no sentido da proposta de Danièle Kergoat, inclusive publicadas antes que ela mesma fizesse a sugestão. 


\section{Referências}

ALBARRACÍN, Jesus. O trabalho doméstico e a lei do valor. In: FARIA, Nalu; NOBRE, Miriam (orgs). O trabalho das mulheres: tendências contraditórias. São Paulo: SOF, 1999.

ARRIAGADA, Irma. Estruturas familiares, trabalho e bem-estar na América Latina. In: ARAÚJO, Clara; PICANÇO, Felícia; SCALON, Celi (orgs). Novas conciliações e antigas tensões? Gênero, família e trabalho em perspectiva comparada. Bauru: Edusc, 2007.

BEDREGAL, Ximena. Con mi feminismo mirando al Sur. Disponível em http://www.creatividadfeminista.org. Acesso em 15/03/2007.

BENSTON, Margareth. A political economy of womens's liberations. Monthly Review, vol. 21, 4, september 1969. Apud FARIAS, Zaíra Ary. Domesticidade: cativeiro feminino? Rio de Janeiro: Achimé/CMB, 1983.

CARDOSO, Irede. Os problemas das donas de casa. Folha de São Paulo. São Paulo, 18 de abril de 1982. P. 60.

CARRASCO, Cristina. Por uma economia não androcêntrica: debates e propostas a partir da economia feminista. In: SILVEIRA, Maria Lucia da; TITO, Neuza. Trabalho doméstico e de cuidados. Por outro paradigma de sustentabilidade da vida humana. São Paulo: SOF, 2008.

CHABAUD, Danielle; FOUGEYROLLAS-SCHWEBEL, Dominique. Sobre a autonomia relativa da produção e da reprodução. In: KARTCHEVSKY-BULPORT, Andrée (et. al.). $O$ sexo do trabalho. Rio de Janeiro: Paz e Terra, 1986.

COMBES, Daniele; HAICAULT, Monique. Produção e reprodução. Relações sociais de sexos e de classes. In: KARTCHEVSKY-BULPORT, Andrée (et. al.). O sexo do trabalho. Rio de Janeiro: Paz e Terra, 1986.

COSTA, Mariarosa Dalla. Las mujeres y la subversión de la comunidad. In: El poder de la mujer y la subversión de la comunidad. México: Siglo Vientiuno, 1975. Apud FARIAS, Zaíra Ary. Domesticidade: cativeiro feminino? Rio de Janeiro: Achimé/CMB, 1983.

DUPONT, Cristine. O inimigo principal. In: Liberação da mulher: ano zero. Belo Horizonte: Interlivros, 1978. Apud FARIAS, Zaíra Ary. Domesticidade: cativeiro feminino? Rio de Janeiro: Achimé/CMB, 1983.

DURAN, Maria Angeles. A dona de casa: crítica política da economia doméstica. Rio de Janeiro: Edições Graal, 1983. 
HAKIKI-TALAHITE, Fatiha. Por uma problemática do processo de trabalho doméstico. In: KARTCHEVSKY-BULPORT, Andrée (et. al.). O sexo do trabalho. Rio de Janeiro: Paz e Terra, 1986.

HENAUT, Mirta. De la rueca a la red. La economia sumergida. Buenos Aires: Ediciones Corregidor, 2001.

KERGOAT, Danièle. Em defesa de uma sociologia das relações sociais. Da análise crítica das categorias dominantes à elaboração de uma nova conceituação. In: KARTCHEVSKYBULPORT, Andrée (et. al.). O sexo do trabalho. Rio de Janeiro: Paz e Terra, 1986.

PEDRO, Joana Maria. Narrativas fundadoras do feminismo: poderes e conflitos (19701978). Revista Brasileira de História. São Paulo: ANPUH, vol. 26, nº 52, jul/dez 2006.

PINTO, Céli Regina Jardim. Uma história do feminismo no Brasil. São Paulo: Editora Fundação Perseu Abramo, 2003.

SAFFIOTI, Heleieth. Emprego Doméstico e Capitalismo. São Paulo: Vozes, 1978.

TABAK, Fanny. A dona-de-casa no Brasil. In: DURAN, Maria Angeles. A dona de casa: crítica política da economia doméstica. Rio de Janeiro: Edições Graal, 1983. P. 67-68.

TORRES, Cristina. El trabajo doméstico y las amas de casa - el rosto invisible de las mujeres. Mujer y Trabajo $\mathrm{n}^{\circ}$ 2. Montevideo: CIEDUR, 1988. 